\title{
Growth, development and maintenance of American water shrews (Sorex palustris) in captivity
}

\author{
Roman W. Gusztak and Kevin L. Campbell \\ Department of Zoology, University of Manitoba, Winnipeg, Manitoba, Canada, R3T 2N2
}

\begin{abstract}
This paper documents a cost-effective method for the long-term housing and maintenance of water shrews. Wild-caught American water shrews (Sorex palustris) were successfully maintained in this set up for up to 2 years, suggesting a maximum lifespan of 28 months for this species in captivity. In addition, we describe the postnatal growth and development of S. palustris based on data collected from two litters born in captivity, together with corresponding changes in maternal mass over the gestational and postpartum periods. Minimum gestation for this species is 21 days with neonatal mass at birth averaging $0.42 \mathrm{~g}(n=3)$. This study recorded one of the fastest growth rates to date for any Sorex shrew $(0.51 \mathrm{~g} / \mathrm{day})$, with body mass beginning to plateau by 23 days of age. During the last two weeks of pregnancy, body mass of one pregnant shrew increased from 16.0 to $22.8 \mathrm{~g}(0.45 \mathrm{~g} /$ day $)$. Maternal mass quickly dropped by 5 to $7 \mathrm{~g}$ following birth. However, maternal body mass then gradually increased by ca. $20 \%$ during the 24 to 27 day lactation period, despite a $>30$ fold increase in litter mass over this same interval. Exposure of young to water was initiated on day 25 with only surface swimming occurring on this day. All shrews were observed diving the following day, and appeared to be fully proficient divers by 40 to 45 days of age.
\end{abstract}

Key words: American water shrew, gestation, growth, postnatal development.

Shrews constitute one of the more speciose mammalian families (335 recognized species; Wolsan and Hutterer 1998), yet only limited data regarding their postnatal growth and development are available (Vlasák 1972; Vogel 1972a; Hellwing 1973; Hooven et al. 1975; Forsyth 1976; Nesterenko and Ohdachi 2001). From a comparative standpoint, American water shrews (Sorex palustris) provide a good model system to study ontogeny because they are one of the largest representatives of the Tribe Soricini ( $\sigma^{7}: 13-18 \mathrm{~g}$, ㅇ : 8-12 g; van Zyll de Jong 1983). In addition, because $S$. palustris is the world's smallest mammalian diver (Calder 1969), the development of its semi-aquatic habits is of considerable interest. This species is also well suited for conducting carefully controlled laboratory studies of diving behaviour and physiology. However, such studies are only meaningful if animals can be maintained for extended durations in an environment that fosters natural activities.

In this paper, we document the postnatal growth and development of captive American water shrews together with data on maternal mass changes during the gestational and postpartum periods. In addition, we describe an economical self-contained housing unit for the longterm maintenance of water shrews and other small semiaquatic mammals.

\section{Materials and methods}

\section{Animal collection}

A total of 37 American water shrews were livetrapped immediately adjacent to the water's edge along riverbanks and sedge meadows at Nopiming and Whiteshell Provincial Parks, Manitoba, Canada, using Sherman live traps $(256 \times 76 \times 76 \mathrm{~mm})$ baited with dead minnows. A mixture of water shrew feces and soil obtained from the containers of captive-held shrews (see below) was placed at the mouth of each trap to enhance capture success (Sorenson 1962). Traps were checked at 2-hr intervals and, upon capture, shrews were immedi-

*To whom correspondence should be addressed. E-mail: campbelk@ms.umanitoba.ca 


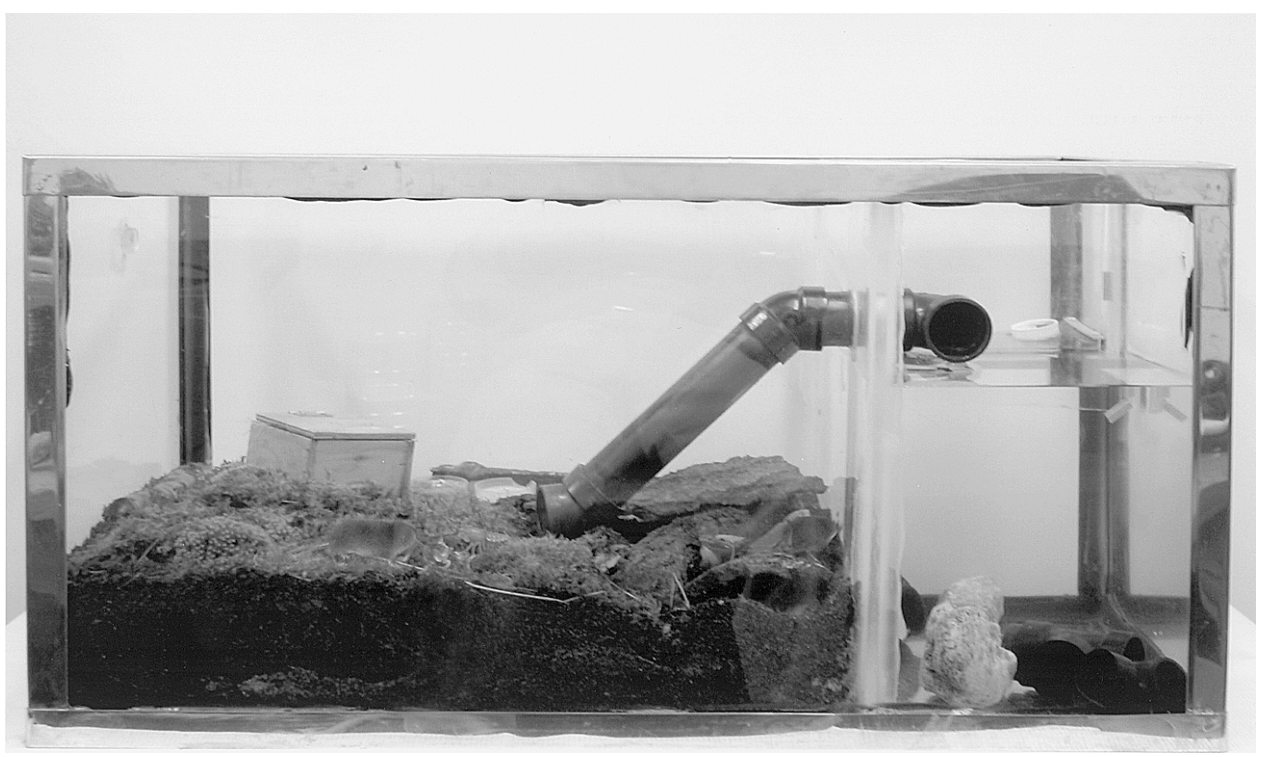

Fig. 1. Modified holding container for the long-term maintenance of captive water shrews (see text for details).

ately transferred to individual 38-1 plastic containers furnished with a screen cover and 5 to $10 \mathrm{~cm}$ of moist topsoil, peat moss and sand. Small logs, bark, rocks and a $100 \times 125 \times 125 \mathrm{~mm}$ wooden nest box were included with this setup to provide cover, together with a feeding platform and water dish. Shrews were presented with a ground mixed ration of beef and chicken heart, pig and beef liver, ground beef, fish fillets and canned dog food enriched with calcium and multivitamin supplements. This diet was supplemented with powdered dry cat food (Purina), hulled sunflower seeds, mealworms (Tenebrio molitor) and sow-bugs (Oniscus asellus). On the morning following capture, all animals were transported back to the University of Manitoba Animal Holding Facility.

\section{Maintenance in captivity}

Shrews were housed individually in large glass aquaria $(88 \times 50 \times 60 \mathrm{~cm})$ situated in a walk-in controlled environment room set to $20 \pm 1{ }^{\circ} \mathrm{C}$ with a $12 \mathrm{~L}: 12 \mathrm{D}$ photoperiod. Each tank was fitted with a 1-cm thick Plexiglass partition that divided the aquaria into aquatic and terrestrial compartments (Fig. 1). The terrestrial section, comprising ca. $75 \%$ of the tank, was filled with $10 \mathrm{~cm}$ of the soil mixture described above and furnished with tree branches, bark, rocks and a nest box. Leaves and dried grass cuttings were provided to foster natural nest building activities, and a piece of moss (ca. $30 \times 30 \mathrm{~cm}$ ) placed in the terrestrial portion of the tank to encourage burrowing. This latter provision has been shown to be necessary for maintaining the hydrophobic properties of the fur of European water shrews, Neomys fodiens (Vogel 1990; Köhler 1991). The terrestrial and aquatic compartments were connected by a $35-\mathrm{cm}$ section of ABS pipe (40-mm internal diameter). A removable acrylic panel, submerged to a depth of $2 \mathrm{~cm}$, was placed between two platforms attached to diagonal corners of the aquarium (Fig. 1). The outer platform was equipped with a feeding tray for the mixed meat ration, thus requiring the shrew to swim across the tank and dive under the partition each time it wanted to feed. Shrews were offered a fresh ration of meat mixture every $12 \mathrm{hr}$, and dragonfly nymphs, leeches, crayfish or mealworms periodically placed in the aquarium to encourage natural diving and foraging behaviours. In addition, rocks and small sections of ABS tubing at the bottom of the tank fostered exploratory diving behaviour. Water in the 24-cm deep aquatic compartment was changed daily. A wire-mesh screen (5-mm hardware cloth) stapled to a wooden frame covered the tank, preventing shrews from escaping.

\section{Pregnancy and postnatal development}

Observations on two pregnant female water shrews captured near midnight June 6th, 2002 along Black River, Nopiming Provincial Park $\left(50^{\circ} 45^{\prime} \mathrm{N}, 95^{\circ} 20^{\prime} \mathrm{W}\right)$ were initiated on the day following capture (June 7 th). To monitor changes in body mass, animals were provided access to a blind-ending, pre-weighed short length $(15 \mathrm{~cm})$ of ABS tubing. Once shrews entered the darkened tube, a cap was placed over the entrance and the unit weighed to the nearest $0.01 \mathrm{~g}$ on a Mettler (model 
PM4600) analytical balance.

Studies on the first litter were initiated on the second day following birth (day 2), whereas those on the second litter were obtained only on the day of birth (day 0 ). The sex of newborns was not determined. Once the mother was captured for weighing, the nest box containing the young was removed from the holding chamber and nestlings individually lifted out and placed in a warm grasslined glass bowl (to prevent escape) for weighing. All weights were recorded daily between 1200 and $1500 \mathrm{hr}$. Shrews were then placed onto a heated metal tray lined with graph paper $(1 \mathrm{~mm} \times 1 \mathrm{~mm}$ square $)$, several digital photographs taken (Nikon Coolpix 5000), and their activities documented. Nestlings were then placed back in the nest box and returned to the holding container. The female was released from the weighing tube back to the holding container following this step. To minimize human scent, latex gloves were worn at all times and all objects in contact with study animals were first washed and then rubbed with soil.

Images were downloaded to computer and measurements of body, hind foot and tail length recorded to the nearest $0.1 \mathrm{~mm}$. Individual nest mates were not marked, however, we were able to track individual changes from identifiable physical features specific to each animal. A form of the Chapman-Richards equation was used to model the increase in body mass and hind foot length: $y(t)=A[1-q \exp (-r t)]^{1:(1-m)}$, where $q=\left(1-y_{0} / A\right)^{(1-m)}$, $\mathrm{A}=$ asymptote, $\mathrm{r}=$ growth rate parameter, $\mathrm{m}=$ shape of curve parameter and $\mathrm{y}_{0}=$ mass at $t_{0}$ (Baud et al. 1997). Means are presented as $\pm 1 S E$.

\section{Results and discussion}

\section{Maintenance in captivity}

The holding containers described above proved to be highly successful in the long-term maintenance of water shrews. Conaway (1952) and van Zyll de Jong (1983) speculated that the maximum lifespan of free-ranging American water shrews does not exceed 18 months. However, we have used this set up to successfully maintain water shrews for up to 24 months. In addition, wild-caught adults often survived for up to 16 months, implying a maximum lifespan of about 28 months for this species in captivity. Similarly, European water shrews are presumed to survive only a single winter in the wild (Vogel 1972b), but can live up to 4 years in captivity (Köhler 1991).

\section{Pregnancy and gestation}

Data on litter size of $S$. palustris is sparse compared to other shrews, although six embryos appear to be most common (Conaway 1952; van Zyll de Jong 1983). Of the two pregnant females obtained, litters of three and four were born on the second and twentieth day following capture, respectively. Thus, 21 days appears to be a minimum gestational period for this species. Similarly, European water shrews (10-20 g) and vagrant shrews, S. vagrans (3-9 g) have a 20-day gestation period (Vogel 1972b; Hooven et al. 1975), while crowned shrews, $S$. coronatus (ca. 9 g), common shrews, $S$. araneus (ca. $10 \mathrm{~g}$ ) and Graves shrews, $S$. isodon (7-17.5 g) have gestational periods of $24,21.5$ and 18 days, respectively (Innes 1994).

On the day following capture the second female weighed $16.01 \mathrm{~g}$ (Fig. 2). Beginning approximately 2 weeks before parturition, the mass of this female increased linearly by an average of $0.45 \mathrm{~g} /$ day, reaching a maximum mass of $22.77 \mathrm{~g}$ on the day preceding birth. This mass is slightly higher than that $(20.48 \mathrm{~g})$ of the other female on the day preceding parturition.

In the two days following birth, both females exhibited a 5 to $7 \mathrm{~g}$ decrease in mass. Interestingly, though one female abandoned her litter at birth while the other reared her young to weaning, the masses of both females were remarkably similar over the first 30 days following parturition (Fig. 2). In this context, it is noteworthy that the nursing female gradually increased body mass by about $3.3 \mathrm{~g}$ (ca. $20 \%$ ) over the 24 to 27 day lactation interval, despite a $>30$ fold increase in the mass of her litter over this same period. Following the weaning of young (see below), the mass of this female gradually declined from $18.05 \mathrm{~g}$ at day 27 to $13.15 \mathrm{~g}$ by day 41 (Fig. 2), where it remained (range: $13.10-14.79 \mathrm{~g}$ ) for the following three months.

\section{Postnatal development}

Newborn. Of the four shrews born in the second litter, one appeared to be stillborn while the remaining young died ca. 4 to 6 hours following birth. A subsequent examination revealed that the female failed to nurse these offspring. The stillborn shrew weighed $0.37 \mathrm{~g}$, while the remaining shrews from this litter had a mean live weight of $0.42 \mathrm{~g}(0.38-0.47 \mathrm{~g})$ and measured 21.5 to $23.5 \mathrm{~mm}$ from crown to rump. All were hairless with transparent skin, and had an attached umbilicus protruding ca. $1 \mathrm{~mm}$ from the abdomen (Fig. 3). Colouration was dark pink to light red dorsally and ventrally except 


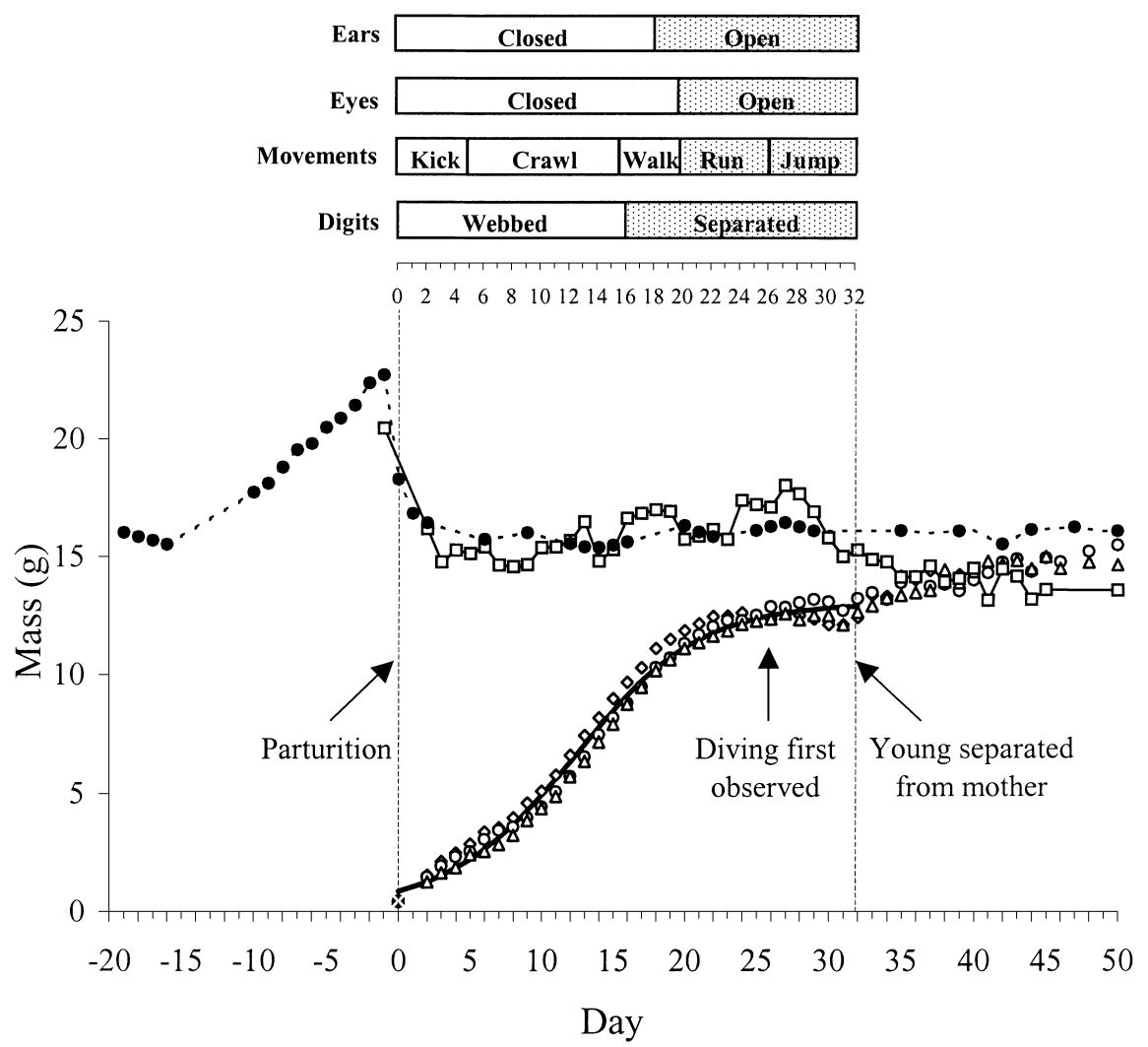

Fig. 2. Growth and developmental changes of three young water shrews, and body mass dynamics of two adult females during the gestational, postpartum and post-lactation periods. Body mass recordings for individuals of litter 1 (open symbols; $n=3$ ) started on day 2 whereas recordings from litter 2 (closed symbols; $n=3$ ) were obtained only on the day of birth (day 0 ). The growth curve was fitted by the Chapman-Richards equation (see text for details).

for the internal organs that appeared as a darkened band across the abdomen. The front appendages stuck out perpendicularly from the body wall while the back limbs and tail curved underneath the body. The digits were clawless and completely fused in both sets of appendages.

Facial features of newborns were noticeable yet lacked clarity. The most evident feature was the blunt, protruding snout. Although two distinguishable nostrils were apparent, vibrissae were absent. The eyes appeared as darkened spots against the red skin and had barely discernable closed eyelids. A slight depression in the ears was evident as the pinnae were fused to the head.

Body mass. The change in body mass of young followed a sigmoid pattern (Fig. 2). This pattern of weight gain, modelled after the Chapman-Richards equation, yielded the following parametric values: $\mathrm{A}=13.046$, $\mathrm{R}=0.231, \mathrm{M}=1.889$, with $\mathrm{y}_{0}=0.42 \mathrm{~g}$.

The average mass of newborns was $0.42 \mathrm{~g}$, or $2.8 \%$ of adult body mass [ $15 \mathrm{~g}$; this study]. Interestingly, this birth weight is lower than that observed in long-clawed shrews, S. unguiculatus ( $0.6 \mathrm{~g}, 4.2 \%$ of adult mass [14.4 g]; Nesterenko and Ohdachi 2001) and $N$. fodiens (0.62 g, 3.4\% of adult mass [18 g]; Michalak 1987), and only slightly higher than that observed in the newborns of markedly smaller soricids: the masked shrew, $S$. cinereus $(0.28 \mathrm{~g}, 7.2 \%$ of adult mass [3.9 g]; Forsyth $1976)$ and $S$. vagrans $(0.35 \mathrm{~g}, 5.9 \%$ of adult mass [5.9 g]; Hooven et al. 1975). However, compared to these other species, S. palustris exhibited an accelerated rate of mass gain during development. For instance, during the early stages of development, S. palustris exhibited a slow, linear rate of weight gain averaging $0.38 \pm 0.02 \mathrm{~g} /$ day and thus attained a mean weight of $4.15 \pm 0.28 \mathrm{~g}$, or $28 \%$ of adult body mass by 9 days of age (Fig. 2). The rate of increase in mass of $S$. unguiculatus, $S$. cinereus and $S$. vagrans during similar stages in development ranged only from 0.20 to $0.23 \mathrm{~g}$ /day (Hooven et al. 1975; Forsyth 1976; Nesterenko and Ohdachi 2001). The maximal rate of weight gain by $S$. palustris occurred from days 10 to $19(0.67 \pm 0.01 \mathrm{~g} /$ day $)$, with shrews exhibiting an average mass of $10.94 \pm 0.34 \mathrm{~g}(73 \%$ of adult 

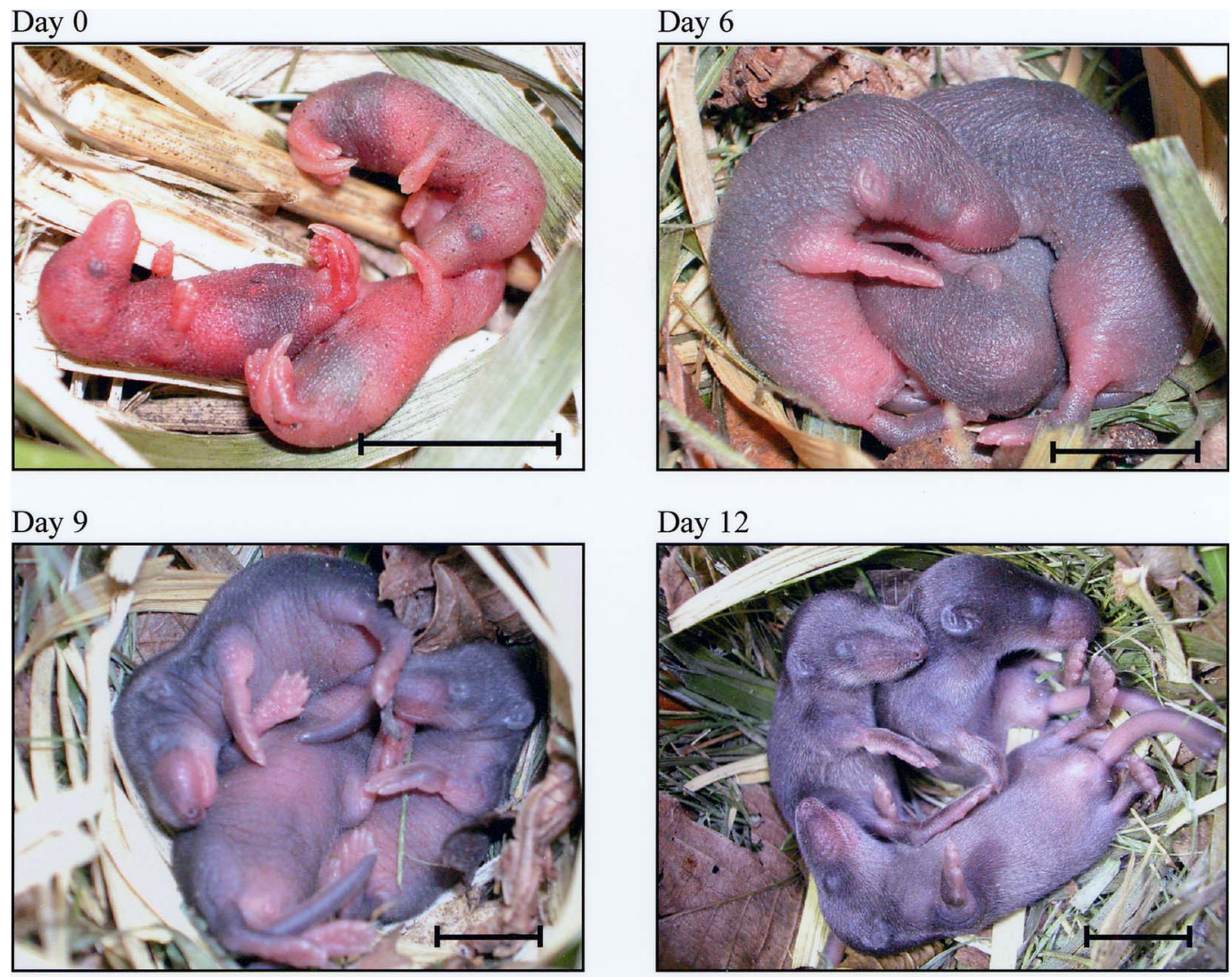

Day 12
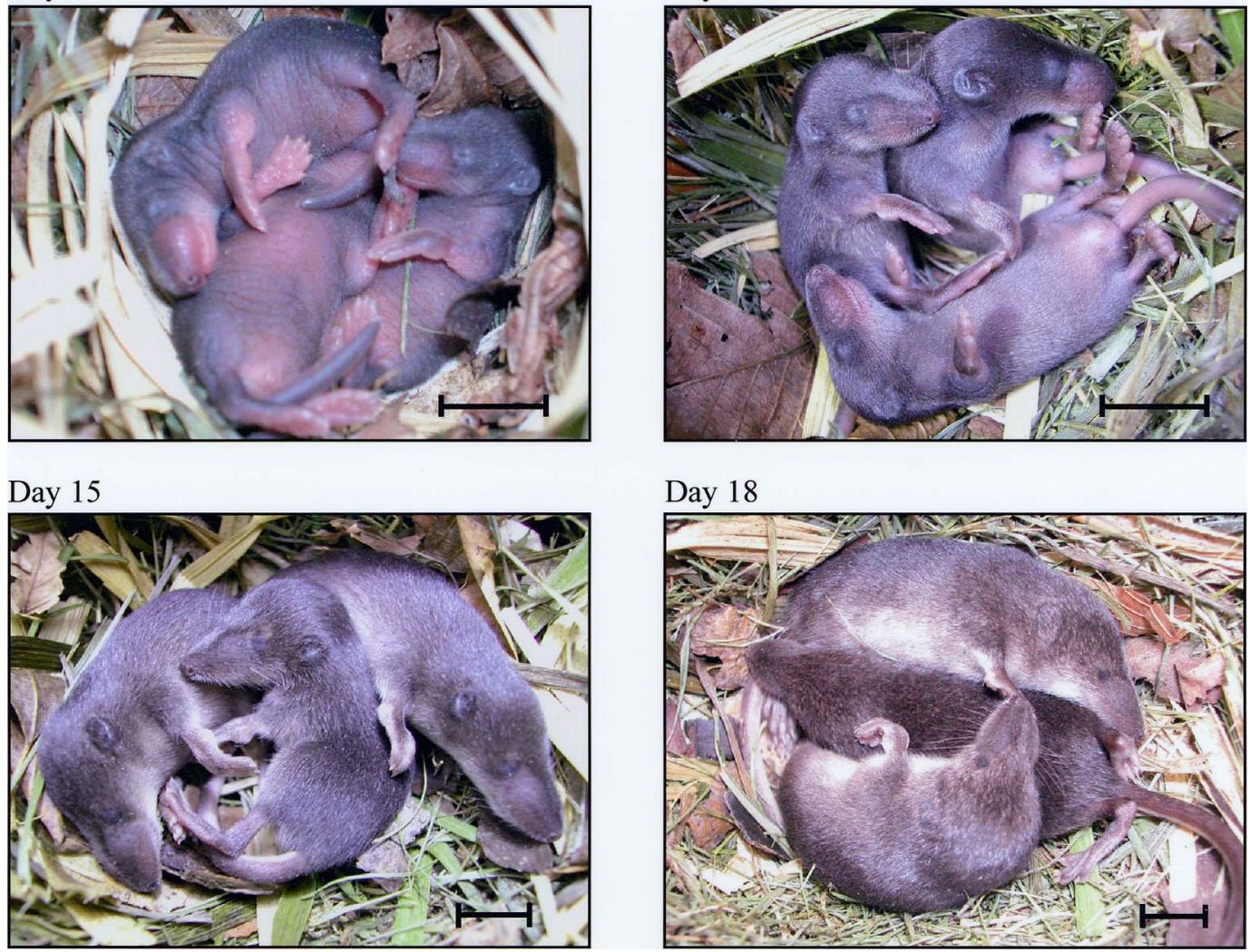

Day 18

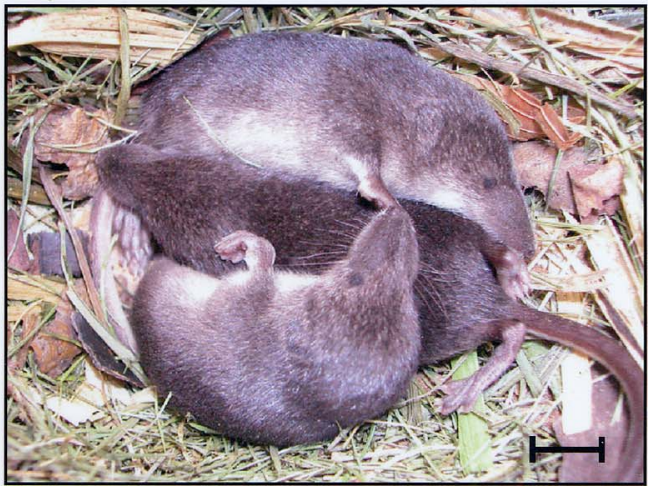

Fig. 3. Physical appearance of nestling American water shrews at days $0,6,9,12,15$ and 18 of development. Scale bar represents 10 mm.

body mass) by day 19. Again, this rate of increase exceeded that of $N$. fodiens and other Sorex shrews $(0.3-$ $0.51 \mathrm{~g} /$ day) examined to date.

Body mass was similar for two of the three individuals during development, while the third shrew was consistently heavier. The greatest mass difference between the largest and smallest shrew was $1.08 \mathrm{~g}$ (day 15). Body mass began to plateau by day 23 (Fig. 2), comparable to that of long-clawed shrews and European water shrews (Vogel 1972a; Michalak 1987; Nesterenko and Ohdachi 2001), but substantially later than that observed for vagrant and masked shrews (16-17 days; Hooven et al. 1975; Forsyth 1976). These data suggest that larger bodied shrews require an extended period of growth to attain adult mass compared to the cohorts of smaller bodied species.

The Chapman-Richards equation we employed predicts a body mass plateau of $12.91 \mathrm{~g}$ at 32 days of age (Fig. 2). This mass is $14 \%$ greater than the mean (11.31 $\pm 0.35 \mathrm{~g} ; n=17$ ) we recorded for recently weaned, wildcaught juvenile water shrews. It appears to be common for free-ranging and captive shrews to exhibit a decline 
in body mass following weaning (Vogel 1972a; Forsyth 1976; Michalak 1987), and a similar, albeit slight, drop in mass was also observed in individuals of our litter between days 26 and 31 (Fig. 2).

Pelage. The transparent nature of the pinkish-red skin was gradually replaced by grey pigmentation that was noticeable by day 4 , with the epidermis darkening first on the dorsal cranium and torso. By day 5 , grey pigmentation also covered the dorsal surfaces of the hind feet and tail, and ventrally along the neck. This gave rise to a distinct bi-colouration on the body and tail (Fig. 3). On day 6 , grey pigmentation appeared dorsally on the forefeet, and the internal organs were no longer visible as the skin acquired a reddish tint. By day 7 , a fine layer of guard hairs emerged on the body and tail. Noticeable white guard hairs appeared on the underbelly by day 10 , with grey pelage appearing the following day. By day 12 , the ventral side of the neck and torso were distinctly white. The underbelly remained grey until days 14 and 15 when it gradually acquired a brilliant white sheen. The juvenile pelage was complete by 18 days of age with no other significant changes occurring after this time (Fig. 3). Thick fringe hairs (termed fibrillae) found on the inner and outer regions of the front and rear feet of water shrews were noticeable by day 16. By day 23, fibrillae were $1.25 \mathrm{~mm}$ in length, the average size for adult shrews (Beneski and Stinson 1987).

By 25 days of age, the tails of our captive born water shrews were covered with a dense growth of guard hairs. Wild-caught juvenile water shrews were observed to possess a similar covering. In both groups, these guard hairs were noted to gradually thin over time, being nearly bare within three months of birth or capture. Interestingly, the tails of wild-caught adults were invariably found to be either completely hairless or to possess only a few white hairs on the tip. Thus, this feature appears to be a physical characteristic ideal for distinguishing adults from young of the year while collecting free-ranging American water shrews.

Ears, eyes and teeth. The pinnae were completely fused with the head at birth and began protruding from the skull by day 4 . A distinct invagination in the ear was noticeable on day 6 , with pinnae darkening in colour until day 9 when they appeared black and leathery. Fine hairs emerged from the pinnae on day 14, and by day 19 the ears were almost indistinguishable on the head. The external auditory meatus apparently opened on day 18 as shrews started reacting to noises produced by the authors by this time. By comparison, $N$. fodiens first perceive sound on day 19, while the ears of $S$. cinereus and $S$. araneus open between days 14 and 17 (Vogel 1972a; Forsyth 1976).

As the shrews became older, the increased facial pigmentation made the black eye spots less distinctive (day 5). The first signs of eyelid formation were noticeable on day 7 and became more distinct with age such that the upper and lower half of each eyelid started to bulge by day 12 . By day 17 , shrews were noted to actively avoid light. The eyes partially opened on day 20 and were completely open by day 21 . Likewise, the eyes of vagrant and European water shrews reportedly open at 21 , and between 20 and 24 days of age, respectively (Hooven et al. 1975; Michalak 1987). However, the eyes of common, long-clawed and masked shrews open by days 9, 15 and 17-18, respectively (Forsyth 1976; Innes 1994; Nesterenko and Ohdachi 2001).

Limited data was collected for teething as the authors did not forcibly open the mouths of the young, but instead looked for emerging teeth when the young voluntarily opened their mouths. Rear teeth began erupting on day 21 , and by day 24 the characteristic brownish-red colour was apparent on the tips of the teeth. In European water shrews, teeth begin to appear on day 25 , with eruption being complete by day 28 (Vogel 1972a).

Digits and claws. The fusion between the digits gradually became less pronounced, and by day 11 the paws possessed a webbed appearance throughout their length. The lateral digits on the front and back feet separated by day 15 , while the medial digits became free on day 16 . There was no difference in separation time for the front or back digits. Michalak (1987) noted digit separation for young $N$. fodiens to range from days 13 to 19 , with the phalanges becoming free earlier on the fore foot than the hind foot. Translucent claws emerged by day 5 on the front and rear digits, and were $1 \mathrm{~mm}$ long by day 13 .

Hind foot and tail length. Hind foot length (HFL) and tail length (TL) of newborn shrews averaged 3.3 and 6.2 $\mathrm{mm}$, respectively. HFL increased linearly with age (age in days $=-3.69+1.35 \mathrm{HFL}, r^{2}=0.985, n=59$ ), attaining a length of $20.8 \mathrm{~mm}$ by 26 days, well within the range reported for adult $S$. palustris (18-22 mm; Beneski and Stinson 1987). Growth of the tail was best described by the Chapman-Richards curve with the following parametric values: $\mathrm{A}=65.442, \mathrm{R}=0.172, \mathrm{M}=2.081$ with $\mathrm{y}_{0}=6.3 \mathrm{~cm}$. From this model, the predicted TL $(57.3$ $\mathrm{mm}$ ) of water shrews at 26 days of age was within the lower range typical for adults (57-89 mm; Beneski and Stinson 1987). 
Behaviour. Newborns could not crawl, but made feeble kicking motions and rolled from side to side. By day 3 , young could perform simple crawling motions that primarily consisted of moving the forearms. Crawling became more efficient once all four appendages were used in turn (day 5). On this day, shrews also exhibited a 'righted response' by being able to roll over independently onto their stomachs when placed on their back. By day 7, shrews could burrow into the grass of their nest box and were actively crawling over one another by day 9. Young shrews were able to fully support their body weight and awkwardly walk by days 18 to 19 . Running was first observed on day 20 , and jumping on day 26.

Grooming was first observed on day 12. After this date, young shrews routinely groomed themselves in short 1-2 sec bursts with either their fore or hind feet. Not surprisingly, this behaviour was especially pronounced following bouts of swimming and diving (see below).

High-pitched squeaking noises were first detected on day 13, similar to that found for European water shrews (Michalak 1987), but substantially later than noted for long-clawed (4 days; Nesterenko and Ohdachi 2001) and masked shrews (5-8 days; Forsyth 1976).

For the first 20 days following birth, young shrews were invariably found huddled together in the nest box (and covered by blanket of dried grass) with the mother usually present. One shrew was observed voluntarily leaving and returning to the nest box on day 21 . The following day, all three young were seen walking around the holding container, prompting the inclusion of three additional nest boxes to the holding tank. Despite the addition of these nest boxes, young shrews were always found huddled together, often in different nest boxes each subsequent day. One of the nest boxes became a 'designated latrine site' and was cleaned daily by the authors. After day 23, the mother shrew was usually found in a different nest box from the young and would only return to suckle them. Whenever young encountered and tried to suckle their mother outside the nest box, a brief, aggressive confrontation occurred. The mother reacted by loudly squeaking and running away, but was often pursued a short distance (about $10 \mathrm{~cm}$ ) by the young. Young continued to explore the holding container more each day, and were frequently observed using underground tunnels constructed by their mother.

Aquatic activity. Because young shrews were initially not observed to use the aquatic portion of the holding tank (or enter the ABS tubing leading to it), they were briefly placed in a separate container with dry land and a shallow water section on day 25 to document their swimming behaviour. Two of the three shrews were initially hesitant to enter the water and only did so after a few attempts while the third shrew entered upon first contact with the water. Aquatic locomotion consisted of rapid paddling of the front and rear feet, and was accompanied by rapid corkscrew-like motions of the tail. Aquatic activity was confined to short bouts (ca. 5-10 sec) of surface swimming. However, one individual briefly placed its head under the water in what appeared to be an attempted dive. Upon surfacing, beads of water formed on the shrew's head, suggesting the fur had already acquired its water repellent nature. On day 26 , shrews immediately began diving and were able to dive the width of the aquarium $(50 \mathrm{~cm})$ in $2-3 \mathrm{sec}$. Upon emerging from the water, shrews vigorously groomed their face and torso, alternating between the two areas. Grooming lasted up to 1 min depending on the duration of time in the water and level of activity while grooming. Shrews often re-entered the water immediately following grooming. On day 27, young shrews were observed diving in the aquatic portion of the holding container and by days $40-45$, the diving behaviour and average dive durations of juveniles were indistinguishable from those of wild-caught sub-adults and adults (Gusztak et al., unpublished data).

Weaning. On day 21, shrews were offered meat, pill bugs and mealworms. Animals were observed to smell these items, however no attempts were made to eat. The consumption of particulate food in the holding container was first observed between days 25 and 26. Coinciding with this behaviour, black adult-like feces were observed in the latrine nest box. Prior to this, young excreted semi-solid green feces with high water content, presumably due to their milk-based diet. Thus, young $S$. palustris appear to wean between days 24 and 27 . By day 31 , the mother was actively competing for and stealing food from the mouths of her offspring. Young continued to huddle and sleep together up to day 32 , following which time each was placed in a separate holding container.

External parasites. On day 17, four fleas were noticed and collected from one of the young. A total of 41 fleas (21 ơ, 20 क ) (Corrodopsylla curvata curvta) were obtained from the three young water shrews during daily handling over the next 10 days, and were presumably contracted from the nest or mother. This species of flea 
is common to shrews and star-nosed moles (Condylura cristata) from our collection locale, and have previously been reported for American water shrews (Conaway 1952).

Acknowledgments: We are indebted to Ian McIntyre, Chris Schneider and Robert Senkiw for their assistance in live trapping and caring for shrews in captivity, and to Dr. Darren Gillis for assistance in modelling growth curves. Dr. Terry Galloway, Department of Entomology, University of Manitoba, kindly identified and sexed the flea specimens. The cooperation of the Parks and Natural Areas and Wildlife and Ecosystems Protection Branches of the Manitoba Department of Natural Resources is acknowledged. The constructive comments of two external reviewers were gratefully appreciated. R.W.G. was supported in part by a University of Manitoba Faculty of Science Undergraduate Student Research Award in both 2001 and 2002. This study was funded by a discovery grant to K.L.C. from the Natural Sciences and Engineering Research Council (NSERC) of Canada.

\section{References}

Baud, J. P., Gerard, A. and Naciri-Graven, Y. 1997. Comparative growth and mortality of Bonamia ostreae-resistant and wild flat oysters, Ostrea edulis, in an intensive system. I. First year of experiment. Marine Biology 130: 71-79.

Beneski, J. T., Jr. and Stinson, D. W. 1987. Sorex palustris. Mammalian Species 296: 1-6.

Calder, W. A. 1969. Temperature relations and underwater endurance of the smallest homeothermic diver, the water shrew. Comparative Biochemistry and Physiology A 30: 1075-1082.

Conaway, C. H. 1952. Life history of the water shrew (Sorex palustris navigator). The American Midland Naturalist 48: 219-248.
Forsyth, D. J. 1976. A field study of growth and development of nestling masked shrews (Sorex cinereus). The Journal of Mammalogy 57: 708-721.

Hellwing, S. 1973. The post-natal development of the white-toothed shrew Crocidura russula monacha in captivity. Zeitschrift für Säugetierkunde 38: 257-270.

Hooven, E. F., Hoyer, R. F. and Storm, R. M. 1975. Notes on the vagrant shrew, Sorex vagrans, in the Willamette Valley of western Oregon. Northwest Science 49: 163-173.

Innes, D. G. L. 1994. Life histories of the Soricidae: a review. In (J. F. Merritt, G. L. Kirkland, Jr. and R. K. Rose, eds.) Advances in the Biology of Shrews (Carnegie Museum of Natural History Special Publication 18). Pp. 111-129. Carneige Museum of Natural History, Pittsburgh.

Köhler, D. 1991. Notes on the diving behaviour of the water shrew, Neomys fodiens (Mammalia, Soricidae). Zoologischer Anzeiger 227: 218-228.

Michalak, I. 1987. Growth and postnatal development of the European Water Shrew. Acta Theriologica 32: 261-288.

Nesterenko, V. and Ohdachi, S. D. 2001. Postnatal growth and development in Sorex unguiculatus. Mammal Study 26: 145-148.

Sorenson, M. W. 1962. Some aspects of water shrew behaviour. American Midland Naturalist 68: 445-462.

van Zyll de Jong, C. G. 1983. Handbook of Canadian Mammals. 1 Marsupials and Insectivores. National Museums of Canada. 210 pp.

Vlasák, S. 1972. The biology of reproduction and post-natal development of Crocidura suaveolens Pallas, 1811 under laboratory conditions. Acta Universitais Carolinae-Biolofica, 1970: 207-292.

Vogel, P. 1972a. Vergleichende Untersuchung zum Ontogenesemodus einheimischer Soriciden (Crocidura rusulla, Sorex araneus und Neomys fodiens). Revue Suisse de Zoologie 79: 1201-1332.

Vogel, P. 1972b. Beitrag zur Fortpflanzungsbiologie der Gattungen Sorex, Neomys, and Crocidura (Soricidae). Verhandlungen der naturforschenden Gesellschaft in Basel 82: 165-192.

Vogel, P. 1990. Body temperature and fur quality in swimming watershrews, Neomys fodiens (Mammalia, Insectivora). Zeitschrift für Säugetierkunde 55: 73-80.

Wolsan, M. and Hutterer, R. 1998. A list of the living species of shrews. In (J. M. Wojcik and M. Wolsan, eds.) Evolution of Shrews. Pp. 425-448. Mammal Research Institute, Polish Academy of Sciences.

Received 26 January 2004. Accepted 27 April 2004. 